\title{
Increased risk of gastro-oesophageal cancers among married couples: Data from the Ardabil Cancer Registry (ACR) in Northwest of Iran, 2002-2016
}

Manouchehr Iranparvar-Alamdari

Gastrointestinal Cancer Research Center, Ardabil University of Medical Sciences, Ardabil, Iran

Abbas Yazdanbod

Gastrointestinal Cancer Research Center, Ardabil University of Medical Sciences, Ardabil, Iran

Nasrollah Maleki ( $\sim$ malekinasrollah@gmail.com)

Hematology-Oncology and Stem Cell Transplantation Research Center, Tehran University of Medical Sciences, Tehran, Iran https://orcid.org/0000-00031511-7052

Majid Rostami-Mogaddam

Department of Dermatology, Imam Khomeini Hospital, Ardabil University of Medical Sciences, Ardabil, Iran

Farnaz Amani

Gastrointestinal Cancer Research Center, Ardabil University of Medical Sciences, Ardabil, Iran

\section{Research Article}

Keywords: Stomach Neoplasms, Spouses, Environmental Exposure

Posted Date: January 13th, 2021

DOI: https://doi.org/10.21203/rs.3.rs-143888/v1

License: (c) (1) This work is licensed under a Creative Commons Attribution 4.0 International License. Read Full License 


\section{Abstract}

Background: The study of cancer in spouses may play an important role in the assessment of cancer etiology. This study aims to evaluate the risk of gastrooesophageal cancers among spouses.

Methods: We performed a retrospective cohort study of the Ardabil Cancer Registry (ACR) office for patients with a diagnosis of gastro-oesophageal cancers from 2002 to 2016 . Data were collected by trained medical personnel through medical records.

Results: A total of 2741 participants diagnosed with gastro-oesophageal cancer were enrolled in this study: 1786 (65.2\%) had gastric cancer and 955 (34.8\%) had oesophageal cancer. In the 14 years of the study period, twelve couples with gastro-oesophageal cancer were identified. The mean duration at marriage among the couples was 42.5 years of age. A positive history of consanguineous marriage was found in 2 (16.7\%) of the cases. Of these 12 couples with gastro-oesophageal cancer, 8 (33.3\%) were located in the oesophagus, 15 (62.5\%) in the stomach, and one (4.2\%) at the gastro-oesophageal junction. Histologically, all gastric cancers were adenocarcinoma and were located mainly in the cardia region (66.7\%). However, squamous cell carcinoma was the most common histologic type of oesophageal cancer (87.5\%) and were located mainly in the middle thirds and lower thirds of the oesophagus.

Conclusions: The presence of shared risk factors among married couples such as lifestyle (smoking and alcohol consumption), nutritional habits, psychological stress, and $\mathrm{H}$. pylori infection, indicating that environmental factors play an important role in the development of gastric cancer.

\section{Introduction}

Cancer is considered as one of the most common causes of death worldwide. In Iran, cancer ranks the third most common cause of death following cardiovascular diseases and motor vehicle accidents [1]. Overall, gastric cancer rates are estimated to be almost twice as high in men as in women and vary widely across countries. In general, incidence rates are highest in Eastern Asia (particularly in Korea, Mongolia, Japan, and China), Central and Eastern Europe, and South America and lowest in Northern America and most parts of Africa [2]. Based on the GLOBOCAN database, In Iran, gastric cancer is the most common cancer in male and it is reported to be the third cancer after Breast and Colorectal cancers in female [3].

However, the incidence rate of gastric cancer in Iran remains very high; at approximately 26.1 and 11.1 per 100,000 person-years in men and women, respectively [4]. In Iran, the highest incidence of gastric cancer was reported from the Ardabil province. The reported incidence rate of gastric cancer in Ardabil province is 49.1 and 25.4 per 100,000 person-years in men and women, respectively [5]. Gastro-oesophageal cancers alone account for $35.4 \%$ of all cancers in Ardabil province. Gastric cancer is the most common cancer in this region and accounts for nearly one-quarter (23.7\%) of all malignancies [6]. The main risk factors of gastric cancer in Iran include H. pylori infection, H. pylori virulence antigens vacA-i1, atrophic gastritis, high salt intake, smoking, low fruit and vegetable intake, low selenium, and consumption of red meat [7].

The study of cancer in spouses may play an important role in the assessment of cancer etiology. So far, no studies have been done to evaluate the risk of gastro-oesophageal cancers among spouses, and this is the first study on this subject. In the present study, we used data from the Ardabil Cancer Registry (ACR) to estimate the risk of gastro-oesophageal cancers among long-standing spouses. We also assessed the clinical epidemiological characteristics of these couples.

\section{Materials And Methods}

Ardabil Cancer Registry (ACR). The Ardabil Cancer Registry (ACR) is a population-based cancer registry that is located in Aras Clinic in Ardabil city. ACR is currently run by Ardabil University of Medical Sciences (AUMS) and supervised by the Digestive Disease Research Center (DDRC) since 2002, and it has been a member of the International Agency for Research on Cancer (IARC) since 2005 [8]. Cases reported to ACR were initially checked for duplication, were then defined by codes according to the third edition of the International Classification of Disease for Oncology (ICD-O-3), and were finally entered into a database [9].A series of reports from this registry have been published showing an increasing incidence of gastro-oesophageal cancers [7]. Ardabil Province was found to have the highest rate of gastric cancer in Iran and one of the highest gastric cardia cancer rates in the world, and with the great majority originating from the right side of the cardia [10]. Based on the data from this registry, the rate of gastric cancer is still increasing in Ardabil with age-standardized incidence rates of 51.8 in men and 24.9 in women per 100,000 [11].

The standard upper gastrointestinal endoscopy was performed with Olympus flexible endoscope (Olympus, Keymed, UK) by two experienced gastroenterologists. Biopsy specimens were fixed in 10\% neutral formalin and stained by the hematoxylin and eosin (H\&E) technique. Two experienced pathologists then examined specimens for evidence of cancer. The gastro-oesophageal cancer was classified into four groups: oesophageal adenocarcinoma, oesophageal squamous cell carcinoma, gastric cardia adenocarcinoma, and gastric non-cardia adenocarcinoma. Gastric adenocarcinoma was classified as intestinal or diffuse type.

After Institutional Review Board approval was obtained, we performed a retrospective query of the ACR office for patients with a diagnosis of gastrooesophageal cancers from 2002 to 2016. Patients were categorized by demographic factors (age, sex, and race), marital status, duration of the marriage, location of the tumor, histological type, differentiated grade, and year of diagnosis. Data were collected by trained medical personnel through medical records.

\section{Results}


A total of 3814 participants were enrolled in this study; 2741 participants diagnosed with cancer were assigned to the case group, and 1073 to a matched control group. In the case group, 1786 patients (65.2\%) had gastric cancer and 955 patients (34.8\%) had esophageal cancer. In patients with gastric cancer, 1272 patients $(71.2 \%)$ were male and 514 patients (28.8\%) were female, while in patients with esophageal cancer, 512 patients (53.6\%) were male and 433 patients (45.4\%) were female. There were $2198(80.2 \%)$ married cases.

In the 14 years of the study period, twelve couples with gastro-oesophageal cancer were identified. Table 1 shows the clinical characteristics of these 12 couples. The mean age of diagnosis among patients was 67.58 years and 62.58 years in their husbands. The mean duration of marriage among the couples was 42.5 years of age. A positive history of consanguineous marriage was found in $2(16.7 \%)$ of the cases.

Of these 12 couples with gastro-oesophageal cancer, 8 (33.3\%) were in the esophagus, $15(62.5 \%)$ in the stomach, and one (4.2\%) at the gastro-oesophageal junction. Of the 8 patients with oesophageal cancer, 4 (50.0\%) were located in the middle thirds of the esophagus, and 4 (50.0\%) were at the lower thirds of the esophagus. In addition, the most common location of gastric cancer was cardia region $(n=10 ; 66.7 \%)$, followed by body region ( $n=3 ; 20.0 \%)$, and antrum region $(n=2 ; 13.3 \%)$. Histologically, all gastric cancers were adenocarcinoma. However, squamous cell carcinoma was the most common histologic type of oesophageal cancer, representing $87.5 \%$ of all oesophageal cancers, followed by adenocarcinoma (12.5\%). Only one couple out of these 12 couples had an identical location and pathology of the tumor (cardia region, adenocarcinoma).

\section{Discussion}

The results of this study showed that the proportion of couples with gastro-oesophageal cancer in this retrospective cohort is only $0.4 \%$ (12/2741), 8 (33.3\%) were in the esophagus, $15(62.5 \%)$ in the stomach, and one (4.2\%) at the gastro-oesophageal junction. The study did not show that the risk of gastrooesophageal cancers among spouses was significantly higher than that among the general population. Also, the most common location of gastrooesophageal cancer was the cardia region (41.7\%), followed by the middle third of the esophagus (16.7\%), the lower third of the esophagus (16.7\%), body region (12.5\%), antrum region (8.2\%), and gastro-oesophageal junction (4.2\%), In line with the current results, our previous study showed that the most frequent site of upper gastrointestinal cancer in the gastric cardia (25.3\%) followed by the oesophageal body (18.0\%), antrum (16.4\%), corpus (14.8\%), distal esophagus (11.4\%), the gastro-oesophageal junction (9.4\%), and proximal esophagus (4.4\%) [9].

There is general agreement that gastric cancers are caused by a combination of genetic and environmental factors but these risk factors are only partially identified, and there appear to be different risk factors among different geographical areas of the world, and even among subpopulations within the same area. Although gastric cancer is one of the most common cancers, limited studies have investigated the relationship between familial history and gastric cancer. Of course, it should be noted that this increased risk may not only be due to genetic factors, but it may also be linked to exposure to environmental risk factors among family members [12]. Several environmental factors seem to play an important role in the development of gastric cancer including $\mathrm{H}$. pylori infection, diet, tobacco smoking, and obesity [7].

Shared lifestyle factors seem to be the most important risk factor for the development of gastric cancer. Family members, especially husband and wife, have a shared exposure to environmental carcinogenic agents ( $\mathrm{N}$-nitroso compounds), lifestyle (cigarette smoke and alcohol consumption), nutritional habit (high intake of salt and salt-preserved foods, red meat and refined carbohydrates, as well as low intake of fresh fruits, vegetables, and fish), and infectious agents ( $\mathrm{H}$. pylori infection, and bacterial virulence, such as $\mathrm{H}$. pylori virulence antigens vacA) [13]. In the present study, we investigated the risk of gastrooesophageal cancers among spouses. In cases when both couples were diagnosed with gastro-oesophageal cancers, there may be specific factors that significantly increased their risk levels. We hope that the study of these cases will lead to a successful strategy to reduce the prevalence of gastrooesophageal cancers among spouses.

$\mathrm{H}$. pylori infection is probably the strongest risk factor that has been associated with the development of gastric cancer [14]. According to a report by Uemura et al. [15], gastric cancer developed only in patients infected with H. pylori and none of the uninfected patients. Persons with $\mathrm{H}$. pylori infection and non-ulcer dyspepsia, gastric ulcers, or gastric hyperplastic polyps were also at risk of gastric cancer, but those with duodenal ulcers were not [15]. Based on the guidelines of the Japanese Society for Helicobacter Research, eradication therapy should be given to all patients with $\mathrm{H}$. pylori infection [16]. It has been reported that $\mathrm{H}$. pylori infection rate is very high in the Iranian population. In Ardabil, which is among the regions with highest rate of gastric (predominantly cardia) cancer in the northwest of Iran, the prevalence of $\mathrm{H}$ pylori infection was found to be $89.2 \%$ of adult population [17], which is significantly higher than has been reported in industrialized and developed countries [18]. Possible routes of H. pylori infection include either oral-oral or faecal-oral transmission and iatrogenic spread, through the use of unsterile endoscopes $[19,20]$. Therefore, the infection can easily be transmitted between family members and couples. The high transmission rate of $\mathrm{H}$. pylori infection among family members on the one hand and having a high level of carcinogenicity of this microbe for gastric cancer on the other hand, can justify the increased risk of gastric cancer among couples. Eradication of $\mathrm{H}$. pylori appears to reduce the risk of gastric cancer among family members.

Also, in cases when both couples are diagnosed with cancer, severe psychological stress could affect the entire family. It has been reported that psychological factors such as stress, anxiety, and depression can have an important role in the immune system and may be relevant in the formation of cancer [21].

The results of previous research in Ardabil have shown that diet and $\mathrm{H}$. pylori infection are the strongest known risk factor for gastric cancer. High salt intake, drinking strong and hot tea as well as the consumption of red meat and dairy products, increases the risk of gastric cancer in Ardabil, while high intake of Allium vegetables and fruit, especially citrus fruit and consumption of fresh fish were significantly protective [22]. Furthermore, based on data extracted from published reports, it has been shown that he risk of gastric cancer increase with high intake of fat and sugar, salted and roasted seeds and nuts, and frying, while fruits, vegetables, vitamin C, zinc, and using refrigerator for food preservation had a protective effect of gastric cancer in Ardabil [23].

Page $3 / 6$ 
Cigarette smoking has been associated with an increase in risk for gastric cancer, but the role of passive smoking remains unclear [24]. If a family member smokes at home, the risk of gastric cancer in other family members may likely increase. Therefore, passive smoking might also increase the risk of gastric cancer. A recent review of 42 cohort studies suggested that smoking should be classified as the most important behavioral risk factor for gastric cancer [25]. It has been shown that there is an association of current cigarette smoking with gastric cancer in both sexes, consistency of this effect across five ethnic groups, evidence for a dose-response effect of smoking in both sexes, a stronger effect for cardia than for distal gastric cancer, and a stronger association for intestinal than for diffuse gastric cancer [26]. It has been reported that smoking had a significant association with both gastric cardia and non-cardia cancer in Ardabil [27]. Also, a recent population-based cohort study showed an association between hookah/opium use and gastric cancer in Ardabil Province [28].

In 2014, Liu and colleagues [29] conducted a review of data from 230 husband and wife pairs with malignant tumors among 15,000 people who came to the Department of Cancer Prevention, Chinese Academy of Medical Sciences for cancer screening. Among the 230 husband-wife pairs studied, $30.9 \%$ of the pairs had malignant tumors from the same systemic origin. The authors found that $58.7 \%$ of all the 460 cases were diagnosed with digestive system malignancies, and in $21.7 \%$ of the pairs both the husband and the wife presented with digestive system cancers. When the male spouses were diagnosed with digestive system cancer, more than one-third of the female spouses in those pairs were also diagnosed with digestive system cancers. Also, of the women diagnosed with digestive system cancer, $63.3 \%$ had a spouse who was also diagnosed with digestive system malignant diseases. Colorectal cancer ranked first among digestive system diseases affecting the male spouses in this study, with $14.3 \%$ of the husbands diagnosed. The authors of the study suggested that when wife is diagnosed with cancer, the husband should be screened focusing on lung and digestive system cancers, whereas if the husband was diagnosed with cancer, the wife should be screened focusing on lung, breast, and gynecological cancers [29].

To quantify cancer risks from the shared environment, Hemminki et al. [30] evaluated familial risks for concordant cancers between spouses in common cancers of both sexes. Among the 23 cancer sites considered, only two sites, stomach and lung, showed an increase in incidence rate of concordant cancer among spouses. Furthermore, pancreatic cancer and melanoma were increased in couples where at least one spouse was diagnosed before age 50 . The incidence rate of colon, renal, and skin cancers were unchanged by spouses' concordant cancer. The results from this study revealed that shared lifestyle among spouses seems to explain only a small proportion of cancer susceptibility. Because lifestyles are likely to differ more between parents and offspring than between spouses, familial cancer risks between parents and offspring are likely to be more due to heritable rather than environmental effects [30]. A similar study by Hemminki et al. [31], was conducted again one year later to evaluate the risk of cancer from the shared environment. Among the 18 cancer sites considered, only three sites, stomach, lung and bladder, showed concordant increases of cancer among spouses, standardised incidence ratios ranging only from 1.19 to 1.38 . Additionally, gastric and pancreatic cancer were associated among spouses, as did many cancers which were related to tobacco smoking or human papilloma virus infection. By contrast, standardised incidence ratios of colon, rectal, renal and skin cancers showed no increases among spouses.

In 1990, Walach [32] reported the occurrence of cancer in 46 married couples, which emphasized the role of the possible significance of environmental, nutritional, and contamination factors. In this report, 24 pairs had tumors of the same histopathologic type, and 3 couples suffered from the same tumor, with similar histology. In another study, Walach et al. [33] reported the occurrence of cancer in 195 married couples. The authors found that seven sites of cancer were more frequent in married couples than in the general population, in particular colon, prostate, and breast. Same site tumors were observed in 13 couples versus 6.21 expected in the general population. A combination of carcinoma of the prostate and female breast sites was found in 18 couples versus 5.4 expected in the general population. They concluded that the distribution of cancer sites among married couples are different from the general population. Nanni et al. [34] in a survey of 2720 spouses, conducted in the province of Forli (north eastern Italy), found that the spouses of patients who died from gastric cancer are not at increased risk of gastric cancer death.

It has been shown that survival rate of gastro-oesophageal cancer cases in Ardabil is relatively low. In gastric cancer, only smoking was found to be a significant predictor of survival, while surgery and grade of differentiation were significantly associated with survival of oesophageal cancer. However, tumor morphology, age at diagnosis, radiotherapy, alcohol, and opium consumption could not be identified as significant predictors of survival in patients with gastro-oesophageal cancer [35].

\section{Conclusion}

The proportion of couples with gastro-oesophageal cancer in this retrospective cohort is only $0.4 \%$. The most common location of gastro-oesophageal cancer is the cardia region. Shared lifestyle factors play an important role in the development of gastric cancer. The presence of shared risk factors among married couples such as lifestyle (smoking and alcohol consumption), nutritional habits, psychological stress, and $\mathrm{H}$. pylori infection, indicating that environmental factors play an important role in the development of gastric cancer.

\section{Declarations}

Conflict of Interest: We declare that there is no conflict of interest in our article. This study was approved by the Ethics Committee of the Ardebil University of Medical Sciences, Ardebil, Iran.

Ethical approval: Ethics approval was obtained for this study from the Ethics Committee of the Ardebil University of Medical Sciences. Informed consent was obtained from all individual participants included in the study.

\section{References}


1. Saadat S, Yousefifard M, Asady H, Moghadas Jafari A, Fayaz M, Hosseini M. The Most Important Causes of Death in Iranian Population; a Retrospective Cohort Study. Emerg (Tehran). 2015;3(1):16-21.

2. Torre LA, Bray F, Siegel RL, Ferlay J, Lortet-Tieulent J, Jemal A. Global cancer statistics, 2012. CA Cancer J Clin. 2015;65(2):87-108.

3. Ferlay J, Soerjomataram I, Ervik M, Dikshit R, Eser S, Mathers C, Rebelo M, Parkin DM, Forman D, Bray, F. GLOBOCAN 2012 v1.0, Cancer Incidence and Mortality Worldwide: IARC CancerBase No. 11 [Internet]. Lyon, France: International Agency for Research on Cancer; 2013. Available from: http://globocan.iarc.fr, accessed on December 12, 2013.

4. Sadjadi A, Nouraie M, Mohagheghi MA, Mousavi-Jarrahi A, Malekezadeh R, Parkin DM. Cancer occurrence in Iran in 2002, an international perspective. Asian Pac J Cancer Prev. 2005; 6:359-363.

5. Sadjadi A, Malekzadeh R, Derakhshan MH, et al. Cancer occurrence in Ardabil: results of a population-based cancer registry from Iran. Int J Cancer. 2003;107(1):113-8.

6. Babaei M, Jaafarzadeh H, Sadjadi AR, et al. Cancer Incidence and Mortality in Ardabil: Report of an Ongoing Population-Based Cancer Registry in Iran, 2004-2006. Iranian J Publ Health. 2009. 38(4):35-45.

7. Malekzadeh R, Derakhshan MH, Malekzadeh Z. Gastric cancer in Iran: epidemiology and risk factors. Arch Iran Med. 2009;12(6):576-83.

8. Etemadi A, Sadjadi A, Semnani S, Nouraie SM, Khademi H, Bahadori M. Cancer registry in Iran: a brief overview. Arch Iran Med. 2008 Sep;11(5):577-80.

9. Fritz A, Percy C, Jack A, et al. International Classification of Diseases for Oncology: ICD-O. 3rd ed. Geneva: World Health Organization; 2000.

10. Derakhshan MH, Yazdanbod A, Sadjadi AR, Shokoohi B, McColl KE, Malekzadeh R. High incidence of adenocarcinoma arising from the right side of the gastric cardia in NW Iran. Gut. 2004;53(9):1262-6.

11. Babaei M, Pourfarzi F, Yazdanbod A, Chiniforush MM, Derakhshan MH, Mousavi SM, et al. Gastric cancer in Ardabil, Iran-a review and update on cancer registry data. Asian Pac J Cancer Prev. 2010;11(3):595-9.

12. Foschi R, Lucenteforte E, Bosetti C, et al. Family history of cancer and stomach cancer risk. Int J Cancer. 2008;123(6):1429-32.

13. Lee YY, Derakhshan MH. Environmental and lifestyle risk factors of gastric cancer. Arch Iran Med. 2013;16(6):358-65.

14. The EUROGAST Study Group. An international association between Helicobacter pylori infection and gastric cancer. Lancet. 1993;341(8857):1359-62.

15. Uemura N, Okamoto S, Yamamoto S, et al. Helicobacter pylori infection and the development of gastric cancer. N Engl J Med. 2001;345(11):784-9.

16. Asaka M, Kato M, Takahashi S, et al. Guidelines for the management of Helicobacter pylori infection in Japan: 2009 revised edition. Helicobacter. 2010;15(1):1-20.

17. Malekzadeh $\mathrm{R}$, Sotoudeh $\mathrm{M}$, Derakhshan $\mathrm{MH}$, et al. Prevalence of gastric precancerous lesions in Ardabil, a high incidence province for gastric adenocarcinoma in the northwest of Iran. J Clin Pathol. 2004;57(1):37-42.

18. Eusebi LH, Zagari RM, Bazzoli F. Epidemiology of Helicobacter pylori infection. Helicobacter. 2014;19 Suppl 1:1-5.

19. Vaira D, Holton J, Menegatti M, et al. Routes of transmission of Helicobacter pylori infection. Ital J Gastroenterol Hepatol. 1998;30 Suppl 3:S279-85.

20. Cave DR. How is Helicobacter pylori transmitted? Gastroenterology. 1997;113(6 Suppl):S9-14.

21. Conti CM, Angelucci D, Ferri M, et al. Relationship between cancer and psychology: an updated history. J Biol Regul Homeost Agents. 2011;25(3):331-9.

22. Pourfarzi F, Whelan A, Kaldor J, Malekzadeh R. The role of diet and other environmental factors in the causation of gastric cancer in Iran-a population based study. Int J Cancer. 2009;125(8):1953-60.

23. Pakseresht M, Forman D, Malekzadeh R, et al. Dietary habits and gastric cancer risk in north-west Iran. Cancer Causes Control. 2011;22(5):725-36.

24. Kneller RW, You WC, Chang YS, et al. Cigarette smoking and other risk factors for progression of precancerous stomach lesions. J Natl Cancer Inst. 1992;84(16):1261-6.

25. Ladeiras-Lopes R, Pereira AK, Nogueira A, et al. Smoking and gastric cancer: systematic review and meta-analysis of cohort studies. Cancer Causes Control. 2008;19(7):689-701.

26. Nomura AM, Wilkens LR, Henderson BE, Epplein M, Kolonel LN. The association of cigarette smoking with gastric cancer: the multiethnic cohort study. Cancer Causes Control. 2012;23(1):51-8.

27. Derakhshan MH, Malekzadeh R, Watabe $\mathrm{H}$, et al. Combination of gastric atrophy, reflux symptoms and histological subtype indicates two distinct aetiologies of gastric cardia cancer. Gut. 2008;57(3):298-305.

28. Sadjadi A, Derakhshan MH, Yazdanbod A, et al. Neglected role of hookah and opium in gastric carcinogenesis: a cohort study on risk factors and attributable fractions. Int J Cancer. 2014;134(1):181-8.

29. Liu J, Xu Z, Zhang K, et al. Characteristics of malignant tumors in 230 husband-wife pairs. Cell Biochem Biophys. 2014;70(1):123-7.

30. Hemminki K, Dong C, Vaittinen P. Cancer risks to spouses and offspring in the Family-Cancer Database. Genet Epidemiol. 2001;20(2):247-57.

31. Hemminki K, Jiang Y. Cancer risks among long-standing spouses. Br J Cancer. 2002;86(11):1737-40.

32. Walach N. Married couples and cancer. J Surg Oncol. 1990; 44:62-65.

33. Walach N, Novikov I, Milievskaya I, Goldzand G, Modan B. Cancer among spouses: review of 195 couples. Cancer. 1998;82(1):180-5.

34. Nanni O, Zoffoli G, Scarpi E, Bucchi L, Lauriola P, Cislaghi C, Amadori D. Gastric cancer mortality in the spouses of patients who died from gastric cancer. Int J Epidemiol. 2002;31(2):468-72.

35. Samadi F, Babaei M, Yazdanbod A, et al. Survival rate of gastric and esophageal cancers in Ardabil province, North-West of Iran. Arch Iran Med. 2007;10(1):32-7. 
Table

Table 1 shows the clinical characteristics of couples.

\begin{tabular}{|c|c|c|c|c|c|c|c|c|c|c|}
\hline \multicolumn{6}{|c|}{ Husband data } & \multirow{2}{*}{$\begin{array}{l}\text { Consanguineous } \\
\text { marriage } \\
\text { ( YES / NO) }\end{array}$} & \multirow{2}{*}{$\begin{array}{l}\text { Duration } \\
\text { of } \\
\text { marriage } \\
\text { (years) }\end{array}$} & \multicolumn{3}{|c|}{ Spouse data } \\
\hline & $\begin{array}{l}\text { ID } \\
\text { NUMBER }\end{array}$ & sex & $\begin{array}{l}\text { Age of } \\
\text { diagnosis }\end{array}$ & $\begin{array}{l}\text { Tumor } \\
\text { location }\end{array}$ & pathology & & & $\begin{array}{l}\text { Age of } \\
\text { diagnosis } \\
\text { (years) }\end{array}$ & $\begin{array}{l}\text { Tumor } \\
\text { location }\end{array}$ & Pathology \\
\hline 1 & 2789 & M & 59 & Cardia & $\begin{array}{l}\text { Adenocarcinoma } \\
\text { diffuse type }\end{array}$ & NO & 30 & 57 & $\begin{array}{l}\text { Distal } \\
\text { esophagus }\end{array}$ & $\mathrm{SCC}$ \\
\hline 2 & 1567 & $\mathrm{~F}$ & 59 & $\begin{array}{l}\text { Mid } \\
\text { esophagus }\end{array}$ & Invasive SCC & NO & 37 & 61 & $\begin{array}{l}\text { Distal } \\
\text { esophagus }\end{array}$ & Adenocarcinoma \\
\hline 3 & 1568 & $\mathrm{~F}$ & 75 & Antrum & $\begin{array}{l}\text { Adenocarcinoma } \\
\text { intestinal type }\end{array}$ & NO & 60 & 80 & $\begin{array}{l}\text { Distal } \\
\text { esophagus }\end{array}$ & $\mathrm{SCC}$ \\
\hline 4 & 6566 & M & 83 & $\begin{array}{l}\text { gastro- } \\
\text { oesophageal } \\
\text { junction }\end{array}$ & $\begin{array}{l}\text { Adenocarcinoma } \\
\text { intestinal type }\end{array}$ & NO & 51 & 68 & Cardia & Adenocarcinoma \\
\hline 5 & 6638 & M & 58 & Cardia & Adenocarcinoma & YES & 37 & 47 & $\begin{array}{l}\text { Mid } \\
\text { esophagus }\end{array}$ & $\mathrm{SCC}$ \\
\hline 6 & 1011 & M & 63 & Antrum & Adenocarcinoma & YES & 48 & 70 & Cardia & Adenocarcinoma \\
\hline 7 & 1992 & M & 82 & Body & Adenocarcinoma & NO & 41 & 61 & Cardia & Adenocarcinoma \\
\hline 8 & 6806 & M & 65 & Cardia & Adenocarcinoma & NO & 45 & 64 & $\begin{array}{l}\text { Mid } \\
\text { esophagus }\end{array}$ & $\mathrm{SCC}$ \\
\hline 9 & 0587 & M & 53 & Body & Adenocarcinoma & NO & 23 & 40 & Cardia & Adenocarcinoma \\
\hline 10 & 2386 & $\mathrm{~F}$ & 53 & Body & & NO & 34 & 65 & $\begin{array}{l}\text { Mid } \\
\text { esophagus }\end{array}$ & $\mathrm{SCC}$ \\
\hline & & & & & Adenocarcinoma & & & & & \\
\hline 11 & 6816 & $\mathrm{~F}$ & 71 & Cardia & $\begin{array}{l}\text { Adenocarcinoma, } \\
\text { Intestinal type }\end{array}$ & NO & 53 & 71 & Cardia & Adenocarcinoma \\
\hline 12 & 6847 & M & 90 & $\begin{array}{l}\text { Distal } \\
\text { esophagus }\end{array}$ & SCC & NO & 51 & 67 & Cardia & Adenocarcinoma \\
\hline
\end{tabular}

